\title{
Exploring Effects of Area-Wide Traffic Calming Measures on Urban Road Sustainable Safety
}

\author{
Anna Granà (Corresponding author) \\ Department of Road Railway and Airport, University of Palermo \\ Viale delle Scienze, Ed. 8, 90129 Palermo, Italy \\ Tel: 39-091-488-062Ｅ-mail: anna.grana@unipa.it \\ Tullio Giuffrè \\ Engineering \& Architecture Faculty, Università Kore, Enna \\ Cittadella universitaria, 94100 Enna, Italy \\ Tel: 39-093—536-622 E-mail: tullio.giufre@unikore.it \\ Marco Guerrieri \\ Department of Road Railway and Airport, University of Palermo \\ Viale delle Scienze, Ed. 8, 90129 Palermo, Italy \\ Tel: 39-091-488-062 E-mail: marcoguerrieri@unipa.it
}

The research was supported by the fund - ex quota 60\% - of Research Unit at the University of Palermo 2006 (Analysis of operational conditions and behavioural parameters at not standard roundabouts)

\begin{abstract}
Traffic calming schemes refer to a combination of road network planning and engineering measures to minimize undesirable effects of traffic in residential areas. The traffic calming role in urban road network management is, indeed, to enhance road safety as well as other aspects of liveability for the citizens; in this context accident reduction can be a realistic objective. Several studies highlight that traffic calming treatments can significantly reduce road accidents in urban areas. Nevertheless, the increase of the accident rate per kilometre travelled has been found in urban areas as result of the so-called accident migration phenomenon. Starting from these considerations, the paper discusses the effects of traffic calming measures on road safety. The paper also aims to provide a concise overview of knowledge on the potential of the meta-analysis method in detecting the true effect of traffic calming measures on road safety. Therefore, the role of the road network planning and the characteristics of urban road network that have to be consistent to the traffic calming objectives are examined. Finally, authors suggest a methodological procedure for implementing a traffic calming zone in residential areas, from planning level to road design.
\end{abstract}

Keywords: Traffic calming, Road safety, Urban planning, Residential area

\section{Introduction}

Since 1994, more than 2000 local governments have adopted the principles of the Aalborg Charter as a basis for local sustainability actions (Aalborg Charter, 1994). As a consequence, therefore, local governments have begun to put into effect improvements in living conditions within cities and towns (Van Begin, 2004). Consistent with explicit strategies on sustainability in the urban transport sector, community objectives request to urban planners and designers to include road safety as an essential prerequisite to warrant a sustainable mobility (Wegman et al., 1997; NRSS, 2000; COM, 2001; OECD, 2002; CCMTA, 2002; ETSC, 2003; Koornstra, 2003; Maltby, 2003; Peden et al., 2004; Wong, 2006; COM, 2006; Broughton et al, 2007). The goal of sustainable safe road traffic is indeed to prevent accidents reducing the chance of severe injury to (almost) zero. For this reason a proactive approach is useful because it recognizes people's physical vulnerability, latent errors of road users and their irregular behaviors. So modifications of "road" and the "vehicle" are necessary to meet this human features and education should prepare users for the traffic task (SWOV, 2006). In order to prevent user errors and accident results, the proactive approach to sustainable safety considers that measures have to be taken before system errors occur. In consequence, road safety is less dependent on the individual choices of road users and the responsibility for safe mobility also lies with planners, designers and managers of traffic system components (SWOV, 2006).

Strategies specifically targeted to improve road safety on a sustainable basis follow in general two different aims: a) minimizing the severity of the consequences of hazard behaviors by installing devices adequate to reduce road user damages when accident occurs; b) making the consequences of hazard behaviors more severe by the 
installation of suitable measures alerting users and inducing them to appropriate behaviours. Traffic calming devices are attributable to the last one aim. Acting on driver behaviors they can paradoxically increase the accident rate per $\mathrm{km}$ travelled (Wilde, 1998). Moreover, undesirable effects of traffic calming schemes can be empirically explained by the traffic volume shift from the treated road sections to other roads (Wilde, 1998; Persaud et. Al, 1997). In fact, an in-depth analysis of the effects of different traffic calming schemes and treatments on drivers speed highlights that benefits are generally localized in time and space, but other inconveniences (i.e. the lack of public acceptability, noise and air pollution, possible accident migration) can occur together (Comte et al., 1997; Hidas et al., 1998; Wilde, 1998; Houwing, 2003). Some studies on traffic calming devices show the riskiness related to episodic traffic calming installations, or rather an increase in accidents has occurred after some installations (Calongne, 2003); site-specific measures (i.e., narrowings and median islands) have been also found to be less effective in terms of numbers and severity of pedestrian injuries (Dijkstra \& Bos, 1997). This can limit the confidence in drawing inferences about impacts on road safety of traffic calming (Ewing, 1999). A possible reason is that it is not yet rooted knowledge that in a sustainable vision only an area-wide traffic-calming approach is the most appropriate to solve traffic safety problems in residential areas (Eriksson et al, 2003; Houwing, 2003). The paper on the basis of an oriented literature review aims to perceive the area-wide effects of traffic calming measures on road safety and to consider their role in the road network planning. At last, a methodological framework to follow for the implementation of traffic calming schemes in residential areas, from planning level to road design, is proposed.

\section{Traffic calming benefits, practices and developments}

Local road safety strategies should be considered within or alongside local transport plans. In a sustainable vision the development and the implementation of local road safety strategies are directed to enhance casualty reduction. Traffic calming schemes are an important element in local road safety strategies, but traffic calming schemes may create problems, particularly if road hierarchies and strategic routes have not been brought together (IHT, 1990 and 1997). The effectiveness of a traffic calming scheme as a whole can improve by selecting appropriate measures to meet local objectives. A summary of traffic calming measures can be found in Table 1, as adapted by examining published reports on traffic calming (see as an example LTN 01/07, 2007). It should be noted that similar measures may not always give similar outcomes: for example, the desired reduction in speed will depend on the magnitude of the previous speeds and on the type of selected measures. Moreover, area-wide traffic calming schemes may include a large variety of measures; so it can be very difficult to attribute speed or casualty reductions to specific measures (LTN 01/07, 2007). Some traffic calming schemes consist of only road humps because they can be a good solution to control speeds for many roads. Nevertheless, area-wide schemes can often be enhanced by considering a variety of measures that, blending in with the surrounding area, are more appropriate for the desired speed reduction. The success of area wide traffic calming schemes is not only determined by their good effects on speed, flows, accidents, vehicle emissions, but it depends on the relative public acceptability. Measures soon become discredited if the local public does not like them; so, it is better to estimate the likely public reaction to the scheme before it is installed. In assessing the potential impact of alternative area-wide traffic calming schemes, the use of programs that can predict the likely effects on safety of a scheme (taking also account of possible changes in traffic patterns) may be helpful (LTN 01/07, 2007). In order to meet safety, planning and environmental objectives, good practice recommendations have been developed to outline aspects that should be considered when public attitudes need to be assessed (Scottish Executive, 1999; BPRS, 2007). Information about the most important European Union projects on best practices examples also related to the topic traffic-calming can be find in Traffic Management and Restraint (Ribeiro, 2004).

\section{How to value effects of traffic calming measures on road safety?}

Traffic calming is a useful way of controlling drivers' speeds where speeds are excessive and/or inappropriate for the road type. Justification for installing traffic calming is generally based on improving safety by reducing accidents. Accidents on residential roads (both on access roads and on local-distributor network) are seldom concentrated at specific black spots, but usually scattered over a wide area with highly variable annual accident rates; in this context, localized countermeasures of traffic calming, or traffic calming devices applied to an individual street only, can result not appropriate to contain (or preferably to eliminate) accidents. In order to address this problem, therefore, the use of traffic calming in residential areas needs an area-wide approach to be adopted (LTN 01/07, 2007). From the safety point of view, therefore the implementation of traffic calming measures is based on the assumption that the speed reduction following from traffic calming installations can achieve an effective reduction of accident frequencies and severities (Litman, 1999). Nevertheless, such safety improvement (in terms of accident reductions) can vary greatly depending on environmental and traffic factors of the context passed through: class of road, dimension of the interested area, type of adopted measures, changes in traffic demand.

Evaluation studies of traffic calming effects on road safety include a great variety of researches, differing for year of publication, country of origin, study design and controlled parameters; further differences concern accident severity and type of road to which results refer to (Granà et al., 2008). An exhaustive retrieval of such studies is reported by Elvik et al. (1997) and by Elvik (2001). More recent studies on this subject are referred in 
Taylor et al (2000), Hummel et al (2002), Houwing et al. (2003), Lee (2006). Despite the rich harvest of information one can draw out either the lot of reports by safety research institutes or journals and conference proceedings, in the field of evaluation studies of traffic calming effects on road safety we have to pay for the generally poor reliability of the results. Moreover, most of the time researches in this matter have been carried out applying methodological approaches quite lacking in sound foundations. It has to be highlighted that the analysis of the accident phenomenon, also in the case of the safety evaluation of traffic calming measures, is based on the observation of accidents by empirical approaches, as before-and-after studies; misleading conclusions can essentially derive either from lack in control for regression-to-the-mean (or long-term trends in accident occurrence) or by ignoring the presence of potentially important confounding factors. Example of relevant bias due to regression-to-the-mean can occur in safety evaluation of major (access) roads with high accident number in the before period; lack of control for confounding factors (change in traffic volume, modifications in land use, etc.) can seriously compromise outcomes of area-wide safety evaluations. As it is widely known Hauer (1997) has codified the way to prevent both kind of bias by means of the Empirical-Bayesian approach to the before-and-after observational studies; nevertheless, up to now there are few applications to safety evaluation of traffic calming measures meeting this standard. Few studies consider a matched comparison group and in this way they implicitly control for regression-to-the-mean bias; this, in particular, if the matched comparison area has an equally bad or good accident record as the traffic calming area in the before period (Elvik, 2001). In the absence of EB before-and-after or other kind of sound studies on which traffic calming safety evaluation could be based, an approach by meta-analysis can still provide an effective tool to review literature results and to draw out realistic estimates of traffic calming effects on road safety. This of course cannot remove biased results from source studies, but by means of subjective judgment it allows to establish a hierarchy of values among them on the basis of their objective credit. In this way meta-analysis approach enables to gather and to analyze contributions from different studies starting from the evaluation and the interpretation of their methodological design. A meta-analysis procedure has to provide a way to check the initial hypothesis and the robustness of conclusions to source studies design; at the same time it has to control for "publication bias", a particular bias specially arising in literature retrieval either when results are not statistically significant or when they are regarded as 'unfavourable' or 'negative' (increase in number or severity of accidents). In both cases results are less likely to be published than that statistically significant or "desirable" ones. Next section gives an overview of the conceptual formulation of the meta-analysis method and a critical synthesis of the main results of meta-analysis studies applied to traffic calming schemes.

\section{An overview of the meta-analysis method}

In lots of scientific research sectors the meta-analysis method is the base of analysis procedures directed towards the evaluation of effects of ameliorative measures. The meta-analysis collecting and examining data from different studies on a specific theme can be applied to identify the common effect of a treatment, when this (or the effect size) is consistent from one study to the next. On the contrary, the meta-analysis can be applied to explain the variation when the effect size is not exactly the same in all the studies. The meta-analysis is applied to reach a conclusion on the usefulness of an ameliorative measure, or on the validity of a hypothesis. The decision cannot be based on conclusions of a single study, because the results can vary from a study to another study. The meta-analysis, on the contrary, makes use of suitable formulations to elaborate data from more researches (whatever the number may be), similarly to the elaborations of a single study. This method is directed towards the quantitative estimate of the combined effect (the global effect) of a specific treatment (or a specific variable). The meta-analysis computes a weighted mean of the effect sizes (with more weight given to some studies and less weight given to others), rather than compute a simple mean of the effect sizes. Borenstein et al. (2009) consider two model used in meta-analysis: the fixed effect model and the random effects model. Starting from analogous studies (as regards the modes of the sample selection and/or of the execution of tests), the fixed effect model allows to deduce the common effect of a treatment (or the effect on average). This model assumes only one true effect size, exactly alike in all the analyzed studies. So the combined effect is the estimate of the common effect size. The only reason of variation is imputable to the random error inherent in each study. When assigning weights to the different studies, small studies can be disregarded, because information about the same effect size can be obtained by studies with a wider sample base. The observed effects are thought to be distributed with mean $\mu$, equal in all the studies, and a variance $\sigma^{2}$ depending on the sample size for each study. Therefore, the observed effect is equal to $T_{i}=\mu+{ }_{+}$, where $\quad$ i is the within-study error, i.e. the error correlated to random factors intervened in the sampling within the same population (see Figure 1). When the sample size increases, this error decreases. To minimize the variance of the combined effect, the weight $\left(\overline{F i s}_{\mathrm{B}}\right)$ gned to each study is equal to the inverse of the variance; the inverse variance, roughly proportional to sample size, is computed as $w_{i}=1 / v_{i}$, where $\mathrm{v}_{i}$ is the within-study variance for study $i$. So the weighted mean for the observed effects is:

$$
\overline{T_{0}}=\left(\sum_{i=1}^{k} w_{i} T_{i}\right) /\left(\sum_{i=1}^{k} w_{i}\right)
$$


where the reciprocal of the sum of the weights is the variance of the combined effect. To compute the limits of the confidence interval containing $\mu$ at an assigned probability level see Borenstein et al. (2009).

The random effect model, starting from data collected by different studies on the effect of a treatment and from the evaluation of differences among the studies, allows to value if these differences could be directed towards (or not) a reliable result on the effect of an ameliorative measure. This model assumes that the true effect can change from one study to the next. The examined studies are a random sample of the distribution of true effects; so the combined effect is the mean effect of this distribution. Studies with a large sample size can offer more accurate estimates than small studies, but each study estimates a different effect value; moreover each estimate represents a sample of the population of which the mean would be estimated. Weights assigned under random effects will be more balanced than those assigned under fixed effects, because the random effect model does not give extreme emphasis to studies with a very large sample size or it does not cancel studies characterized by a small sample size. Nevertheless, two sampling levels and two error levels can be considered as possible: a) each study is used to estimate the true effect in a specific sample population; b) all the true effects are then used to estimate the mean of the true effects. As a consequence the estimate of the combined effect depends on two sources of error: the number of elements in each study and the total number of studies. In other words, even if each study has a wide sample base, the estimate of the mean can be not-exhaustive, because the studies have been extracted by all the possible studies. The observed effect $T_{i}$, given $\theta_{i}$, is sampled from a distribution with mean $\theta_{1}$ and variance $\sigma^{2}$, depending on the study sample size. Then the true effect $\theta_{i}$, in turn, is sampled from a distribution with mean $\mu$ and variance $\tau^{2}$ (see Figure 2). The observed effect is equal to: $T_{i}=\theta_{i}+\varepsilon_{i}=\mu+\zeta_{i}+\varepsilon_{i}$, where $\varepsilon_{i}$ is the within-studies error and $\zeta_{\mathrm{i}}$ is the error between studies. In order to consider the two sources of error, the random effect analysis considers the decomposition of the observed variance into two components (within-studies and between-studies) and then the use of both parts in assigning weights. Similarly to the fixed effect model, the random effect model also considers the weight assigned to each study equal to the inverse of the variance (in this case composed by two parts). Nevertheless, the random effects model can be generalized better than the fixed effect model, based on an identical and narrowly defined population.

\subsection{An application of the meta-analysis as a tool to value traffic calming effects}

According to Elvik (2001), the results of a meta-analysis from 33 studies carried out in 8 different countries on traffic calming effects showed that these measures allow a reduction of injury accidents. This reduction is higher for residential streets than for main roads. Damage-only accidents are also interested by similar reductions. Measures that have been included in the meta-analysis varied with regard to the surrounding context (with a residential character and a size over the range $0,25 \div 1,5 \mathrm{~km}^{2}$ ) and to the main traffic function of the road. The reliability of evaluation studies has been valued basing on: a) study organization and applied method; b) traffic volume data; c) accident severity; d) effects on road safety by type of road. The research included before-and-after studies on accidents occurred in presence of traffic calming measures, but no study controlled explicitly for the regression-to-the-mean or temporal trends in the long period. Table 2 shows the variations in the number of accidents distinguished by severity and by type of road. The results related both to the fixed effect model and to the random effect model seem similar and they result significant by a statistical point of view at a 5\% confidence level. The confidence intervals are much wider for the random effect model because the fixed effect model considers only the random variation of effects in each study; on the contrary, the random effect model captures the systematic variation of effects among the examined studies. The reduction of accidents number ranged between 15 and 20 percent in residential areas where traffic calming scheme were installed. Reductions on local roads ranged between 25 and 55 percent, whereas reductions found on main roads ranged between 8 and 15 percent. Results are reasonable because traffic calming measures can reduce traffic volumes and speeds on local roads; on the contrary, these measures can increase traffic volumes on main roads. Another meta-analysis literature review from 16 controlled before-and-after studies was conducted by Bunn et al. (2003) by means of a random effect model. It was found that area-wide traffic calming in towns and cities has the potential to reduce road traffic injuries (up to $11 \%$ for fatal and non-fatal), but no reliable evidence in reducing the number of road traffic accidents was highlighted. This is not inconsistent with a reduction in the occurrence of injuries, since traffic calming primarily reduce vehicle speeds. Authors observe that several methodological issues may have influenced their results and they explicitly warn for the significant heterogeneity between the studies reporting the number of road traffic injuries and accidents. In order to underline the significance of results derived from the meta-analysis (i.e. the combined effect and the variance), it can be useful to establish a comparison with results derived from only one smaller study. As example of this, Brilon and Blanke (1994) report on the effects of area-wide traffic calming measures in six German cities. On the basis of this study we would have to: a) 63 percent reduction, on average, of seriously injured persons in traffic calming areas; b) 50 percent reduction, on average, of injury accidents; c) 23 percent reduction of injury accidents in the studied areas as a whole (including urban arterials and sites without traffic calming measures). The same study showed an increase in accidents in presence of constricted lane widths: there were largely damage-only accidents, which mainly involved buses and trucks. It can be deduced that the meta-analysis including more observations than only one case study, as well as considering lots of factors that can influence the examined phenomenon, can produce more realistic evaluations (closer to the true effect) of safety benefits of traffic calming measures. 


\section{The road network planning related to traffic calming measures}

Traffic calming installations in a specific area has to be founded on a road network planning where sectors with a strong residential connotation are already recognized. There are, however, other areas such as business nodes with a high concentration of pedestrians where traffic calming could be implemented to improve mobility for pedestrians by a road safety point of view, i.e. to protect pedestrians from the adverse impacts of motorized traffic. In the planning and design of traffic calming, it is important to recognize that different road classes have certain important functions and that these functions should not be compromised by the traffic calming measures. So, the functional road classification should be used to resolve the competing needs of mobility and traffic calming of the city. In this regard Vorster et al. (2009) propose: on mobility roads, giving priority to the needs of through traffic or the need of the larger community, but with due consideration for the needs of the local community where it is possible to address such needs; on access roads, giving priority to the needs of residents, but with due consideration for the needs of the larger community where it is possible to address such needs.

In accordance with the principles of sustainable safety proposed by Swov Institute for Road Safety Research (2006) the road network should be functionally subdivided in three main types of roads: 1) through-roads, which allow traffic to flow; 2) access roads, which allow access to destinations; 3) distributor roads, which connect through-roads to access roads. In a sustainable safety vision, urban road-network plans should also be made basing on a classification of roads in different road types on their ability to meet the sustainable safety principles. Nevertheless, there are still several important bottlenecks in the design of the various urban road types (see Table 3 ); sometimes there is insufficient knowledge to tackle them with concrete proposals (SWOV, 2006). It is still very difficult to implement traffic calming on through-roads and distributor roads without significantly affecting traffic flow and measures should therefore mostly be considered on access roads. On higher order roads, traffic calming should only be considered under exceptional circumstances, when the functional integrity of the roads has been compromised by excessive development and the provision of accesses (Vorster et al., 2009).

Traffic calming measures in residential areas generally aim to support the network planning in making residential streets unattractive for through-going motorized traffic and to achieve a constant low speed of the remaining motorized traffic so that it can mix relatively safely with cyclists and pedestrians (Houwing, 2003). This suggests that road network can be structured to avoid that roads with traffic function are within the same area where the main function is the local one. The road network structure has to be characterized by destinations within the same area attainable through the possible shorter distance. Moreover, the existence of infrastructures for alternative transport modes has to be verified to cover the possible removal of road space to motorized traffic.

\subsection{Effects of the area size and of the network structure on traffic volumes and road safety}

The road classification into functional classes is not only a simple attribution of possible functions to each road class, but it makes clear a link between the road geometric design and its use; this link represents a safety prerequisite. The introduction at a network level of traffic calming schemes requests to distinguish the residential function from the traffic function. The residential function is suitable for roads allowing the access to properties at margins or for roads characterized by a strong commercial connotation. The traffic function belongs to distribution roads that are often characterized by high traffic volume at relatively high speeds. To increase the residential function of a road by the implementation of traffic calming measures an analogous function has to be assigned to more next roads to tackle them as a residential street. The positive effects by a safety point of view generally increase with the size of the treated area both for the reduction of the less safe paths within the area, and for the reduction of the number of intersections with main roads, being reduced the needs to cross them. Janssen and Wouters (2003) assert that there is an upper limit for the size of residential areas. This upper limit has to be set by safety, liveability and accessibility criteria: i) if the size exceeds 100 hectare, traffic volumes on the surrounding roads become too large; ii) if the size exceeds 200 hectare, traffic volumes on residential streets can become high, too. Table 4 shows the effects of the size of a residential area on quantitative and qualitative parameters characterizing each of the above-mentioned criteria.

The structure of road network and the number of connections with the higher order distributor roads determine the volume of motorized traffic within the residential area. From a road safety point of view and for environmental reasons through-traffic within the residential area would have to be excluded; traffic volumes in residential areas would need to be as low as possible and they would enter the residential area without large detours. Janssen and Wouters (2003) summarize the most relevant characteristics of three basic network structures for residential areas (see Table 5); they also evaluated the relative score of three types of network structures for four relevant indicators. In particular, organic structures result more consistent to traffic calming criteria than the other two network types: it is best in discouraging through-traffic in residential streets and has the highest safety standard by nature (in fact, they have a large share of T-intersections, which are safer than $\mathrm{X}$-intersections). A point of concern is the central street of the network, which has to carry a relative large amount of approaching traffic (i.e. the origin/destination traffic from and toward the area) and as such it may easily turn into an internal barrier for residents. A solution can be found in increasing the number of non-motorized urban trips at a loss of the number of motorized urban trips. The number of connections between the residential area and the surrounding distributor roads is a characteristic of the network structure with effects 
on the distance travelled inside the residential area and on the distance travelled along the distributor roads. According to Hummel et al. (2002), the analysis of this matter allowed to deduce that the higher the number of connections, the smaller the distance travelled both on residential streets and on the surrounding distributor traffic.

\section{A methodological procedure for implementing a traffic calming zone}

Traffic calming measures can represent a tool for mixing relatively safely traffic components, specially motorized traffic with cyclists and pedestrians. By this point of view, it can be seen as an opposite approach to those accentuating the physical division among mobility components, as a guarantee of sustainable road safety. The segregation of traffic according to traffic function represents a systematic practice suitable for engendering a zone system within road networks scarcely permeable and not much devoted to exchange. Nevertheless, qualitative features and the availability of urban spaces can result negatively affected: vehicles tend to appropriate exclusively the road, as well as aggressive behaviour are led to non-motorized traffic, especially near to the greatest points of conflict. Integrating various traffic components, points of conflicts can increase, but they are characterized by a slower speed and by less aggressive behaviours. This allows a higher level of global safety. According to this, at urban transport planning level, it may be possible to implement traffic calming zones, e.g. zone 30, as the Road Code provides. These zones represent, as the French experiences suggest with reference to installations of analogous measures (CERTU, 1994), a suitable tool to establish a link between the speed limit and the road geometric design in which the afore-mentioned limit is in force. To determine priority factors for traffic calming schemes (i.e. any safety or vehicle speed problems), some monitoring before installation should be made at a local level, so that the results can be used in the initial planning and consultation stages. Table 6 shows a well-known example of priority factors for traffic calming schemes competing for funding developed by Slinn et al. (1998). The synoptic framework depicted in Table 7 represents in a schematic way the articulation through phases (pre-analysis, analysis, synthesis) of the methodological path that brings to the identification of routes and/or areas that are open to be treated by traffic calming measures.

\section{Conclusion}

Traffic calming is a rather broad concept and refers to a combination of urban planning and engineering measures to enhance road safety as well as the living conditions of the urban residents. From road safety point of view, traffic calming in residential areas has to be area-wide rather than applying it to a single street only. The reason is that in residential areas accidents are seldom concentrated at specific black spots, but are scattered over the area. Moreover, it is a common opinion that implementation of area-wide traffic calming measures has positive effects on safety, denoted by reduction of injury or fatal accidents (and injured people); it's also widely held that an overall accident reduction can be a realistic objective as consequence of an urban network management intended mainly to improve safety.

In the paper it has been shown that in absence of sound studies the statistical approach by means of meta-analysis is able to produce more realistic evaluations for safety benefits of traffic calming measures. Apart from safety aspects of the matter, the reasons of integrating traffic calming measures in the network planning process have been underlined with regards to the area size and the network structure effects. The aim of the paper is, indeed, to highlight that benefits of area-wide traffic calming measures are outcomes still to assess. Starting from international experiences, the paper proposes a methodological path for implementing a traffic calming zone. The proposed approach can help the urban transport planner (or the road designer) to the identification of routes and/or areas that are promising to be treated by traffic calming measures. It is also recommended that further research and application be conducted at more sites and for longer time periods to understand better how to plan and to design roads in a sustainable and safe way.

\section{References}

Institution of Highways and Transportation. (1990). Guidelines for Urban Safety Management. The Institution of Highways and Transportation.

Charter of European Cities \& Towns Towards Sustainability. (1994). $1^{\text {st }}$ European Conference on Sustainable Cities and Towns, Aalborg, Denmark [Online] Available: http://ec.europa.eu/environment/urban/alborg.htm (May, 1994).

Ville plus sure, quartiers sans accidents. Réalisations. Evalutations. (1994). CERTU, Juillet, 1994, pp. 253.

Brilon, W., \& Blanke, H. (1994). Area-wide traffic calming measures and their effect on safety in Germany. Conferenza Internazionale vivere e camminare in città, pp. 145 - 155, Italy, 1994.

Comte, S., Varhelyi, A. \& Santos, J. (1997). The Effects of ATT and Non-ATT Systems and Treatments on Driver Speed Behaviour. Working Paper R 3.1.1 in the EU-project - MASTER.

Elvik, R., Mysen, A.B., \& Vaa, T. (1997). Trafikksikkerhetshåndbok (Traffic Safety Handbook, in Norwegian). Oversikt over virkninger, kostnader og offentlige ansvarsforhold for 124 trafikksikkerhetstiltak (Institute of Transport Economics). Oslo: Transportøkonomisk Institutt.

Hauer Ezra. (1997). Observational Before-After Studies in Road Safety. Estimating the Effect of Highway and 
Traffic Engineering Measures on Road Safety. Oxford: Pergamon Press.

Institution of Highways and Transportation. (1997). Transport in the Urban Environment. The Institution of Highways and Transportation.

Dijkstra, A., \& Bos, J. (1997). ACEA - Dutch contribution; road safety effects of small infrastructural measures with emphasis on pedestrians. SWOV, Netherlands.

Persaud, B., Hauer, E., Retting, R., Vallurupalli, R., \& Mucsi, K. (1997). Crash reduction relate to traffic signal removal in Philadelphia. Accident analysis and Prevention, 29, 803-810.

Wegman, F., \& Elsenaar, P. (1997). Sustainable Solutions to Improve Road Safety in the Netherlands, Leidschendam, Institute for Road Safety Research, SWOV Report D - 097 - 8.

Hidas, P., Weerasekera, K. \& Dunne, M. (1998). Negative Effects of Mid-Block Speed Control Devices and Their Importance in the Overall Impact of Traffic Calming on the Environment. Transportation Research D, 3D, 41-50.

Slinn, M., Guest, P., \& Matthew, P. (1998). Traffic engineering design. Principles and practice. MVA Consultancy and Hill Cannon Partnership 1998.

Wilde, Gerald J.S. (1998). Can traffic calming devices be expected to reduce the accident rate per head of population or per unit distance driven? Paper to be presented at the Traffic Safety Summit '98, Kananaskis, Alberta, Canada, Oct. 4-7, 1998.

Ewing, Reid H. (1999). Traffic Calming: State of the Practice, Institute of Transportation Engineers, August 1999, 244 pages. ISBN-13: 978-0935403367.

Litman, Todd. (1999). Traffic Calming Benefits, Costs and Equity Impacts. Victoria Transport Policy Institute. [Online] Available: www.vtpi.org (December, 1999).

Scottish Executive. (1999). The community impact of traffic calming schemes. Central Research Unit, Scottish Executive, Edinburgh.

Slinn, M., Guest, P., \& Mathews, P. (1998). Traffic engineering design. Principles and practice. MVA Consultancy and Hill Cannon Partnership 1998.

National Road Safety Strategy 2001 - 2010. (2000). Australian Transport Council. [Online] Available: www.atcouncil.gov.au (November, 2000).

Taylor, M.C., Lynam, D.A., \& Baruya, A. (2000). The effect of drivers'speed on the frequency of road accidents. TRL Report TRL421. Transport Research Laboratory, Crowthorne, UK.

Elvik Rune. (2001). Area-wide urban traffic calming schemes: a meta-analysis of safety effects. Accident Analysis and Prevention, 33, 327-336.

COM/2001/370, (2001). European transport policy for 2010: time to decide. [Online] Available: http:eur-lex.europa.eu.

Hummel, T., Mackie, A., \& Wells, P. (2002). Traffic calming measures in built-up areas. Literature Review. Unpublished Project Report PR/SE/622/02, TRL. [Online] Available: http://www.vv.se (November, 2002).

Targets and Action Plan. (2002). Annual Report on Road Safety Vision 2010. Canadian Council of Motor Transport Administrators, Transport Canada, Ottawa.

OECD. (2002). Road Safety: What's the Vision? Paris.

Bunn, F., Collier, T., Frost, C., Ker, K., Roberts, I., \& Wentz, R. (2003). Injuries: systematic review and meta-analysis Traffic calming for the prevention of road traffic. Injury prevention, 9, 200-204.

Koornstra, M. (2003). Implications for the EU target and programme. Best in Europe Conference on Targeted Road Safety Programmes in the EU, ETSC, Brussels.

Assessing risk and setting targets in transport safety programmes, European Transport Safety Council. [Online] Available: http://www.etsc.be/documents/riskassess.pdf (Brussels, 2003).

Maltby, C. (2003). Best Value, Local Transport Plans and Road Safety: Listening to and Learning from the Profession, PACTS, January 2003.

Calongne, Kathleen. (2003). Problems Associated With Traffic Calming, published by the National Motorists Association. [Online] Available: www.motorists.org/traffic-calming (January, 2003).

Eriksson, L., Janssen, T., \& Wittink R. (2003). Traffic calming schemes Opportunities and implementation strategies. (The concept of traffic calming: an overview - Chapter 2). Ingrid van Schagen ed., R-2003-22, Leidschendam, 2003, SWOV Institute for Road Safety Research, The Netherlands.

Houwing S. (2003). Traffic calming schemes Opportunities and implementation strategies. (Traffic calming: engineering measures - Chapter 4). Ingrid van Schagen ed., R-2003-22, Leidschendam, 2003, SWOV Institute for Road Safety Research, The Netherlands. 
Janssen T. \& Wouters P. (2003). Traffic calming schemes Opportunities and implementation strategies. (Traffic calming: the role of network planning - Chapter 3). Ingrid van Schagen ed., R-2003-22, Leidschendam, 2003, SWOV Institute for Road Safety Research, The Netherlands.

Peden, M., Scurfield, R., Sleet, D., Mohan, D., Hyder, A., Jarawan, E. \& Mathers, C. (2004). World report on road traffic injury prevention, World Health Organization eds, Geneva.

Van Begin, Gino. (2004). Inspiring Futures for European Local Governments, Local Environment, 9(3), $213-216$. Ribeiro, Anabela. (2004). Summary of projects and results from topic. Traffic management and restraint. FCTUC. [Online] Available: www.eu-portal.net (2004).

Advancing Sustainable Safety. (2006). SWOV Institute for Road Safety Research, Leidschendam (Netherlands). [Online] Available: www.svow.nl (2006).

COM/2006/0314. (2006). Communication from the Commission to the Council and the European Parliament Keep Europe moving - Sustainable mobility for our continent - Mid-term review of the European Commission's 2001.Transport White Paper. [Online] Available: http://eur-lex.europa.eu.

Lee, D. A. (2006). Improving pedestrian safety at unsignalized crossings. TCRP REPORT 112/NCHRP REPORT 562, TRB, Washington DC. [Online] Available: www.trb.org (March, 2006).

Wong, S.C., Sze, N.N., Yip, H.F., Loo, Becky P.Y., Hung, W.T., \& Lo, H.K. (2006). Association between setting quantified road safety targets and road fatality reduction. Accident Analysis and Prevention, 38, 997-1005.

Local Transport Note 01/07. (2007). Department for Transport. Traffic Calming. Published by TSO (The Stationery Office) in the United Kingdom. [Online] Available: www.tsoshop.co.nl (March 2007).

Broughton, J., \& Buckle, G. (2007). Monitoring progress toward the 2010 casualty reduction target, TRL Ltd, Report No. 663, Crowthorne, Berkshire, UK.

Best Practices In Road Safety. (2007). Handbook For Measures At The Country Level - Project funded by the European Commission, [Online] Available: www.eu-portal.net (June, 2007).

Granà, A., Giuffrè, T., \& Guerrieri, M. (2008). Benefits of area-wide traffic calming measures: outcomes still to assess. Lecture presented at The Sustainable City V, Skiathos, Greece, 26 September 2008.

Borenstein, M., Hedges, L.V., Higgins J.P.T., \& Rothstein H. (2009). Introduction to Meta-Analysis. ( $1^{\text {st }}$ ed.). Southern Gate, Chichester, West Sussex, United Kingdom: John Wiley \& Sons Ltd, The Atrium. [Online] Available: www.Meta-Analysis.com (February, 2009).

Vorster, H., Bavusile, R., \& Lambert, F. (2009). Guidelines for the Development of Road Safety Master Plans. Prepared by: Public Works and Infrastructure Development Department Roads and Stormwater Division Traffic Engineering and Operations Section. Version 1.0 (May, 2009). 
Table 1. Summary of measures and their relative performance

\begin{tabular}{|c|c|c|c|c|c|}
\hline \multirow{2}{*}{\multicolumn{2}{|c|}{ type of measure }} & \multicolumn{4}{|c|}{ impact on } \\
\hline & & traffic speeds & traffic flows & injury accidents & $\begin{array}{c}\text { bus/emergency } \\
\text { routes }\end{array}$ \\
\hline \multirow{3}{*}{ 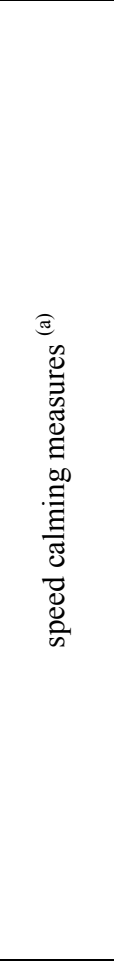 } & 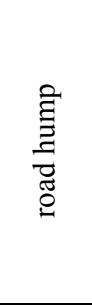 & $\begin{array}{l}\text { Speeds are influenced } \\
\text { by vehicle type* and } \\
\text { hump dimensions. } \\
\text { Speeds between humps } \\
\text { are influenced by } \\
\text { 'before' speed, hump } \\
\text { spacing and dimensions. }\end{array}$ & $\begin{array}{l}\text { Reductions in traffic } \\
\text { flows on average by } \\
25 \text { per cent. }\end{array}$ & $\begin{array}{l}\text { Reductions in injury } \\
\text { accidents of about } 60 \\
\text { per cent**. }\end{array}$ & $\begin{array}{l}\text { Journey times for } \\
\text { buses and delay for } \\
\text { emergency services } \\
\text { can increase; user } \\
\text { discomfort in } \\
\text { bus/ambulance can } \\
\text { be usually higher } \\
\text { than in cars. }\end{array}$ \\
\hline & 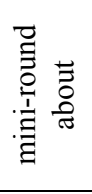 & $\begin{array}{l}\text { Speeds depend on } \\
\text { deflection size (the } \\
\text { bigger the deflection, } \\
\text { the lower the speed). }\end{array}$ & $\begin{array}{l}\text { Inclusion within a } \\
\text { traffic calming } \\
\text { scheme will not } \\
\text { greatly affect } \\
\text { vehicle flows. }\end{array}$ & $\begin{array}{l}\text { Reductions in injury } \\
\text { accidents on average } \\
\text { by } 40 \text { per cent. }\end{array}$ & $\begin{array}{l}\text { Reductions in } \\
\text { delays to emergency } \\
\text { services }\end{array}$ \\
\hline & 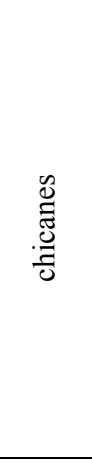 & $\begin{array}{l}\text { Effective speed control } \\
\text { device, but not quite as } \\
\text { effective as road humps. } \\
\text { May not reduce speeds } \\
\text { of two-wheeled motor } \\
\text { vehicles. }\end{array}$ & $\begin{array}{l}\text { May remove some } \\
\text { through traffic but } \\
\text { effects on traffic } \\
\text { flows may be small } \\
\text { (about } 7-15 \text { per cent } \\
\text { overall) } \\
\text { May cause localized } \\
\text { congestion on roads } \\
\text { with high traffic } \\
\text { flow, if dimensions } \\
\text { are too restrictive. }\end{array}$ & $\begin{array}{l}\text { Reductions in injury } \\
\text { accidents on average } \\
\text { by } 47 \text { per cent*** } \\
\text { Collisions with the } \\
\text { kerb build-outs may } \\
\text { increase both } \\
\text { damage-only and } \\
\text { injury accidents. }\end{array}$ & $\begin{array}{l}\text { Less delay to fire } \\
\text { appliances. } \\
\text { Discomfort may be } \\
\text { experienced by } \\
\text { passengers in buses } \\
\text { and ambulances, } \\
\text { depending on } \\
\text { vehicle type, } \\
\text { vehicle speed and } \\
\text { chicane dimensions. }\end{array}$ \\
\hline 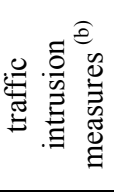 & 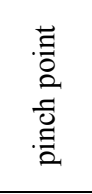 & $\begin{array}{l}\text { Carriageway width is } \\
\text { restricted so that only } \\
\text { one vehicle at a time } \\
\text { may pass (or two cars } \\
\text { can pass slowly). }\end{array}$ & $\begin{array}{l}\text { Medium reduction } \\
\text { in traffic flows }\end{array}$ & $\begin{array}{l}\text { Medium reduction in } \\
\text { injury accidents }\end{array}$ & $\begin{array}{l}\text { High reductions in } \\
\text { delays to emergency } \\
\text { services }\end{array}$ \\
\hline \multicolumn{6}{|c|}{$\begin{array}{l}\text { (a) Speed calming measures aimed at reducing traffic speeds also include raised pedestrian crossing. } \\
\text { (b) These measures also include semi-closures and full closures. Detailed studies are required to ensure that street } \\
\text { closures will not result in traffic intrusion problems in other areas. } \\
\text { (*) Buses, ambulances and commercial vehicles over humps cross at a slower speed than cars. } \\
\text { (**) In } 20 \text { mph zones and on } 30 \text { mph roads in UK. } \\
\left.{ }^{(* *)} \text { Accident data from MOLASSES (web page: } w w w . t r l . c o . u k / m o l a s s e s\right)\end{array}$} \\
\hline
\end{tabular}

Table 2. Results by accident severity and type of road (source: Elvik, 2001)

\begin{tabular}{|l|l|l|l|l|l|}
\hline \multirow{3}{*}{ Accident severity } & \multirow{2}{*}{ type of road } & \multicolumn{4}{|l|}{ Percentage variation in accidents } \\
\cline { 3 - 6 } & & fixed effect model & \multicolumn{2}{l|}{ random effect model } \\
\cline { 3 - 6 } & & estimate & $95 \%$ c.i. ${ }^{*}$ & estimate & $95 \%$ c.i. \\
\hline \multirow{3}{*}{ injury accidents } & area-wide & -15 & $(-17 ;-12)$ & -15 & $(-19 ;-10)$ \\
\cline { 2 - 6 } & main roads & -8 & $(-12 ;-5)$ & -8 & $(-13 ;-2)$ \\
\cline { 2 - 6 } & local roads & -24 & $(-28 ;-18)$ & -34 & $(-43 ;-23)$ \\
\hline \multirow{3}{*}{$\begin{array}{l}\text { damage-only } \\
\text { accidents }\end{array}$} & area-wide & -16 & $(-19 ;-13)$ & -19 & $(-26 ;-12)$ \\
\cline { 2 - 6 } & main roads & -11 & $(-16 ;-6)$ & -18 & $(-31 ;-3)$ \\
\cline { 2 - 6 } & local roads & -29 & $(-25 ;-22)$ & -42 & $(-54 ;-26)$ \\
\hline \multirow{3}{*}{ No data on severity } & area-wide & -19 & $(-25 ;-12)$ & -18 & $(-27 ;-9)$ \\
\cline { 2 - 6 } & main roads & -14 & $(-21 ;-6)$ & -13 & $(-21 ;-4)$ \\
\cline { 2 - 6 } & local roads & -57 & $(-68 ;-43)$ & -57 & $(-68 ;-43)$ \\
\hline
\end{tabular}

$*$ the $95 \%$ confidence interval 
Table 3. Bottlenecks in the actual design of urban road type in the Netherlands (source: SWOV, 2006)

\begin{tabular}{|l|l|}
\hline Road type & Bottlenecks in current urban road design \\
\hline through road & $\begin{array}{l}\text { Old trunk roads (with a single carriageway and a } 100 \mathrm{~km} / \mathrm{h} \text { speed limit) } \\
\text { classified as regional through-road without essential changes: separation of } \\
\text { driving directions, grade separated intersections; grade separated } \\
\text { intersections have been incidentally constructed because expensive }\end{array}$ \\
\hline distributor road & $\begin{array}{l}\text { Speeds of cars at pedestrian and bicycle crossings is often higher than } 30 \\
\mathrm{~km} / \mathrm{h}\end{array}$ \\
\hline access road & Installation is often too low-cost and speeds are often higher than $30 \mathrm{~km} / \mathrm{h}$ \\
\hline
\end{tabular}

Table 4. Criteria to determine the maximum size of a residential area for traffic calming measures installations (source: Janssen T. \& Wouters P., 2003)

\begin{tabular}{|c|c|}
\hline objectives & General and specific criteria \\
\hline 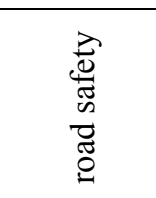 & $\begin{array}{l}\text { Limit the travelled distance within the area (residential and distributor roads) } \\
\text { Limit the traffic volumes within the area } \\
\text { Prevent through-going motorized traffic through the area } \\
\text { Limit speeds of motorized traffic }\end{array}$ \\
\hline 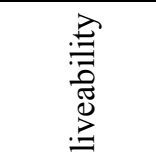 & $\begin{array}{l}\text { Limit traffic volumes in the area } \\
\text { Limit traffic volumes on surrounding distributor roads } \\
\text { Limit speeds of motorized traffic }\end{array}$ \\
\hline 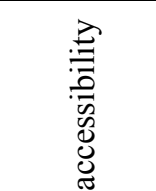 & $\begin{array}{l}\text { Accessibility for cars } \\
\text { Accessibility for emergency response vehicles } \\
\text { Accessibility of urban facilities by pedestrians and cyclists } \\
\text { Accessibility for public transportation }\end{array}$ \\
\hline
\end{tabular}

Table 5. Basic network structures for residential areas (source:Janssen T. \& Wouters P., 2003)

\begin{tabular}{|c|c|c|c|}
\hline \multirow{5}{*}{ the four most relevant indicators. } & \multicolumn{3}{|c|}{ types of residential area network structures } \\
\hline & & + & \\
\hline & & & \\
\hline & \multirow[b]{2}{*}{ Grid network } & \multirow{2}{*}{ Limited access network } & \multirow[b]{2}{*}{ Organic network } \\
\hline & & & \\
\hline Avoidance of through traffic & - & + & ++ \\
\hline Short distances for destination traffic & ++ & + & - \\
\hline Self-induced speed reduction & - & + & ++ \\
\hline $\begin{array}{c}\text { Limited number of connections with } \\
\text { distributor roads }\end{array}$ & - & + & ++ \\
\hline
\end{tabular}


Table 6. Example of priority factors for traffic calming schemes (source: Slinn et al., 1998; LTN 01/07)

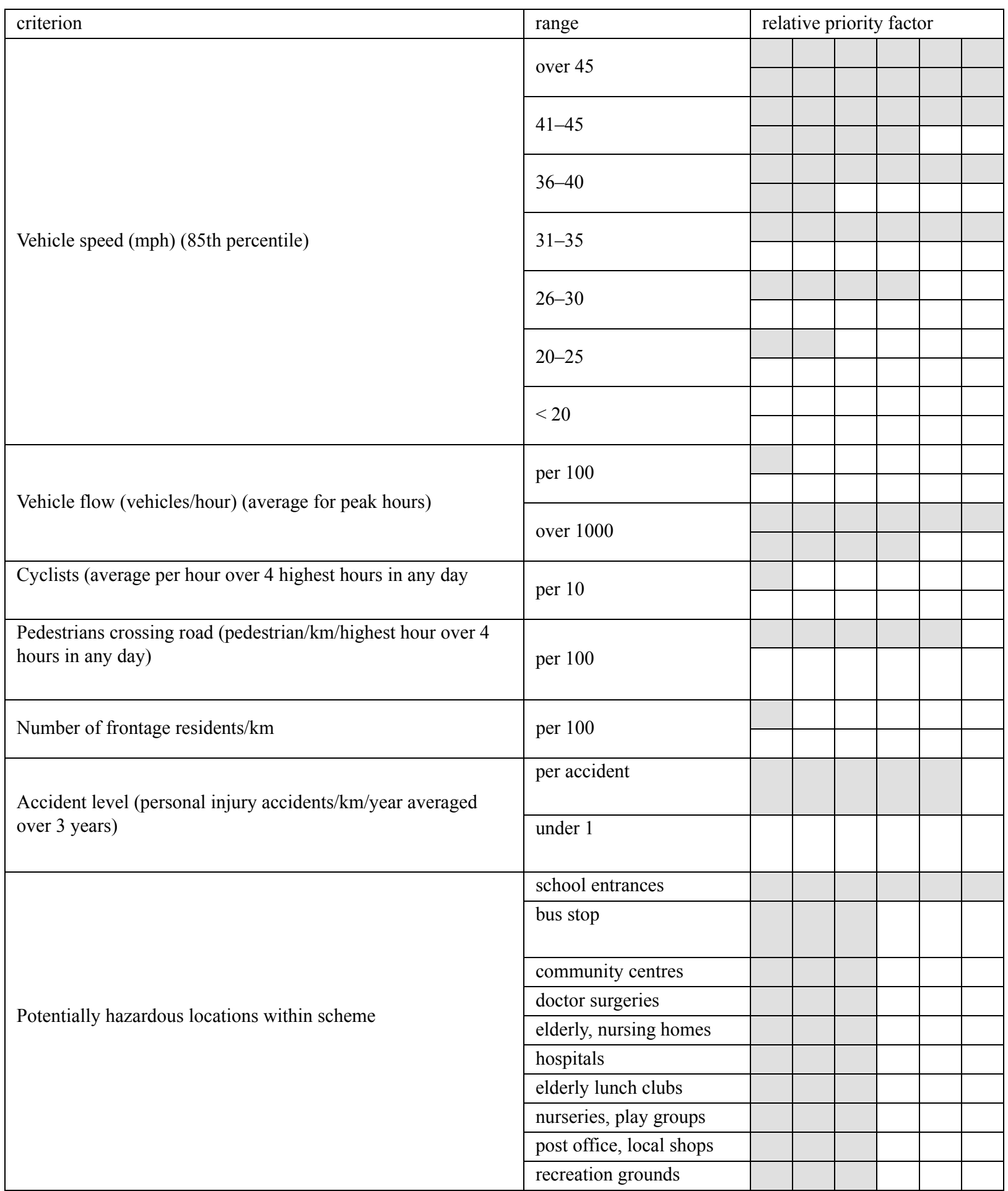


Table 7. The proposed methodological path for the implementation of the zone 30

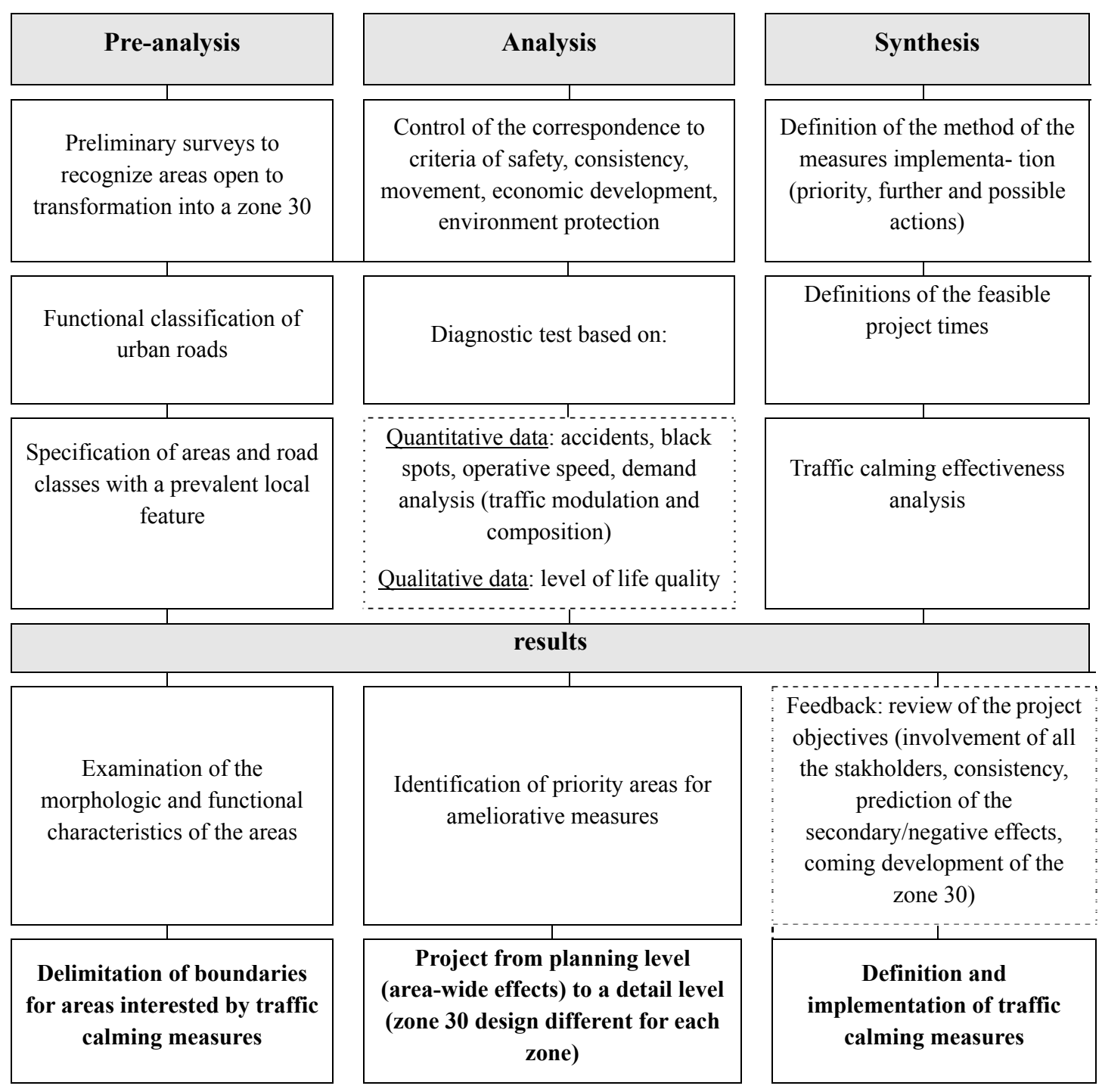

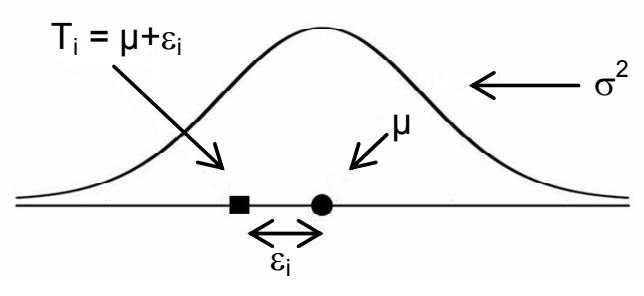

Figure 1. Fixed effect model

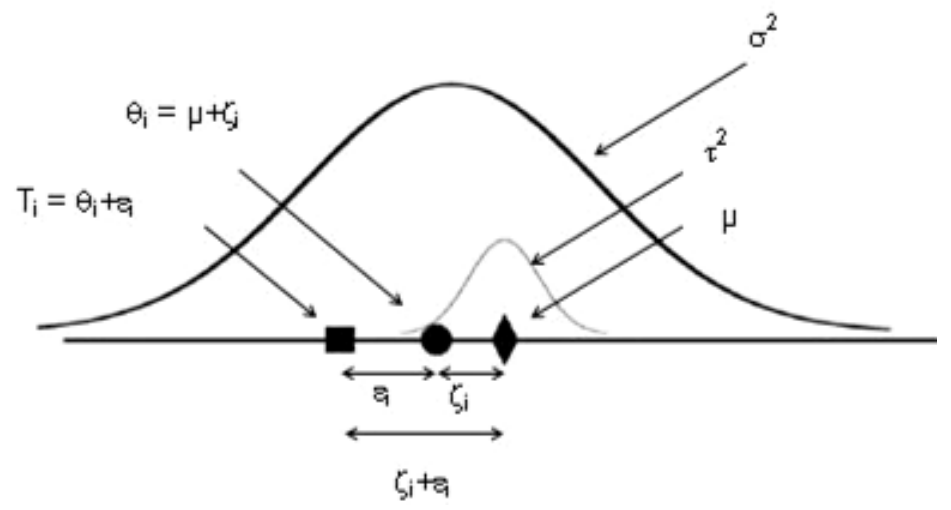

Figure 2. Random effect model 